\title{
Malocclusion and Associated Factors in Early Childhood and Knowledge Level of Mothers from Childcare Groups
}

\author{
Anna Carolina Jaccottet Oliveira ${ }^{1}$, Tuane May de Paula ${ }^{1}$, Denise Faccio Maschio1 ${ }^{1}$, Cleusa Marfiza \\ Jaccottet ${ }^{1}$, Mabel Miluska Suca Salas ${ }^{2}$ (D), Rafael Guerra Lund ${ }^{3}(\mathbb{D}$
}

${ }^{1}$ Faculty of Dentistry, Federal University of Pelotas, Pelotas, RS, Brazil.

${ }^{2}$ Faculty of Dentistry, Federal University of Juiz de Fora, Governador Valadares, MG, Brazil.

${ }^{3}$ Postgraduate Program in Dentistry, Federal University of Pelotas, Pelotas, RS, Brazil.

Correspondence: Prof. Dr. Rafael Guerra Lund, Federal University of Pelotas, Faculty of Dentistry, Gonçalves Chaves St., 457, Pelotas, RS, Brazil.96015-568. E-mail: rafael.lund@gmail.com

Academic Editor: Mohammad Khursheed Alam

Received: 03 August 2020 / Review: 30 November 2020 / Accepted: 13 December 2020

How to cite: Oliveira ACJ, Paula TM, Maschio DF, Jaccottet CM, Salas MMS, Lund RG. Malocclusion and associated factors in early childhood and knowledge level of mothers from childcare groups. Pesqui Bras Odontopediatria Clín Integr. 2021; $21:$ e0177. https://doi.org/10.1590/pboci.2021.074

\begin{abstract}
Objective: To determine the prevalence of malocclusion and associated factors in children and the level of knowledge of mothers participating in the child care group of a basic health unit. Material and Methods: This is a cross-sectional study conducted in children between 18 and 72 months of a childcare group in Pelotas. Children whose parents or legal guardians signed the informed consent term participated in the study. Data were collected through a questionnaire previously tested and applied to the mothers, and a clinical examination of children's occlusion were performed by examiners after training and calibration. Statistical analysis was descriptive and analytic. In the bivariate analyses, it was used the Pearson, Fisher or Linear Trend Qui-Square tests and, in the multivariate analysis, the Poisson regression. Prevalence ratios and $95 \%$ confidence intervals were obtained, and a p-value $<0.05$ was used. Results: Forty-seven children were included and $41.3 \%$ presented malocclusion. The prevalence of malocclusion was associated with a higher number of children in the family $(\mathrm{p}<0.005)$ and breastfeeding for more than 12 months $(\mathrm{p}<0.05)$. The highest prevalence of open bite was associated with the use of a pacifier and working mothers $(\mathrm{p}<0.05)$. Conclusion: Most mothers reported having knowledge about the time and use of pacifiers in childhood. In this group, the prevalence of malocclusion in children was high and associated with behavioral and social factors.
\end{abstract}

Keywords: Malocclusion; Child Care; Pacifiers; Deciduous Tooth; Health Knowledge, Attitudes, Practice. 


\section{Introduction}

Malocclusion is the third priority in oral health after caries and periodontal disease [1]. The prevalence of malocclusion in the primary dentition varies from $20 \%$ to $70 \%$ [1-6]. In children aged 3 to 4 years, the prevalence of malocclusion is highest [1,6]. In Brazil, data from an epidemiological survey showed that $64.4 \%$ of children with 5 years of age present some type of malocclusion, including overjet, overbite or posterior crossbite [7]. Malocclusion is an oral condition resulting from an interaction between genetic and environmental factors [8]. Among the environmental factors, sucking habits, including a pacifier, digital or bottle-feeding used, were associated with malocclusion [1,9-11], being the severity of the deformations depending on the frequency, duration and the intensity of the habits [9,12]. Studies have shown that sucking habits influence the occurrence of anterior open bite, buccal movement of upper incisors, inferior lingual and maxillary constriction [9,12-14]. Breastfeeding of children less than 9 months has been associated with posterior crossbite [4]. Socio-demographic variables were also associated with a higher prevalence of malocclusion in the deciduous dentition, such as low maternal schooling [6,15] and maternal work [16].

The analysis of the factors associated with malocclusion is important for planning public policies regarding the prevention and control of the health problem [8]. Childcare is defined as the set of techniques used to ensure the perfect physical and mental development of the child, from the gestation period up to the age of 72 months, being the prevention and health education the two important pillars [17]. Educational measures are important during childhood, which can prevent early dental loss and control future occurrences of dental or general health problems [18].

Therefore, every contact between the Health Services and the child, regardless of the fact, complaint or illness that motivated it, should be treated as an opportunity for the integrated and predictive analysis of the child's health and for actions to promote health with educational character [19]. After the Oral Health Team (OHT) implantation in the Family Health Strategy (FHS) in the municipality of Pelotas, Brazil, in 2012, actions to promote oral health were implemented. The OHT of the Sanga Funda Basic Health Unit (BUH) developed individual and collective health promotion actions in the childcare program. Thus, during the first programmatic dental consultations, it was possible to observe that most of the children had dental malocclusion, especially anterior open bite, and also that mothers usually offered pacifiers to their children. The aims of the present study were to evaluate the prevalence of malocclusions and possible associated factors and to describe the level of maternal knowledge regarding dental malocclusion of the childcare group at the Sanga Funda FHS in the city of Pelotas.

\section{Material and Methods}

Ethical Clearance

Previously, the project was submitted and approved (Protocol $n^{\circ} 794.038$ ) by the Ethics Committee in Research of the faculty of dentistry of the federal university of Pelotas (UFPel) and by the Oral Health Coordination of the city. An invitation letter explaining the objective of the studies along with the Informed Consent Term (ICT) were sent to the parents or legal guardians. Only the children with the ICT signed participated in the study.

\section{Study Design}

This study was carried out in the city of Pelotas, located in the southern region of Rio Grande do Sul, distant $260 \mathrm{~km}$ from the state capital, Porto Alegre, Brazil. The city has a population of 340,000 habitants, with 
300,952 living in the urban area [20]. This cross-sectional study included children between 18 and 72 months of age participating in the childcare group at Sanga Funda FHS. The FHS attends a population of almost 1,930 families living in the neighborhood of Sanga Funda, an urban district localized far from the downtown and with difficult access, streets without pavement and basic sanitation. The majority of the population works in pottery, have low income and education, and most of them are from rural areas.

The neighborhood has a water supply network; however, some residences still use well water. Childcare and prenatal groups in the BHU attended children from zero to seventy-two months of age. During the study, 162 children participated of the childcare groups. Childcare groups of the BH were divided according to the children's age. One group was specific for children aged 17 months or less and other 4 groups received children with 18 to 72 months of age. The groups with children between 18 to 72 months had activities monthly and were distributed in different weeks of the month. The study had a convenience sample and included two groups of children with 18 to 72 months, totalizing 47 children that participated actively in the childcare groups.

\section{Data Collection}

A previously tested questionnaire based on the literature [7] was applied. The information included socioeconomic and behavioral data such as breastfeeding, bottle feeding, non-nutritive sucking habits (NNSH) and oral health knowledge. The interviews were carried out in the dental office of the BHU to guarantee privacy of the information.

Children's occlusion and dentofacial conditions were assessed based on criteria used in the National Brazilian Dental Survey [7]. The examiner was previously trained and calibrated. Training was performed with 15 children and calibration with 10 children with 5 years old in the school of the health unit area. In this study, the minimum Kappa of 0.7 was considered acceptable for malocclusion [21], being the Kappa obtained 0.86 .

The examinations were carried out by two dentistry students (examiner and recorder), supervised by a dentist, using sterilized individual equipment, photophores, dental mirrors and gauze. For dental malocclusion, four aspects were evaluated: canine occlusion (class I, class II, class III), overjet (normal, increase, edge to edge bite, anterior crossbite), overbite (normal, reduce, open bite, deep bite), anterior maxillary irregularity and posterior crossbite. Children with dental necessities were referenced to the health unit or the dental clinic of the federal university for treatment. Also, children's mothers received guidance on oral health care and healthy habits during the childcare groups meetings. Children's ages were categorized in 18-35 months, 36-48 months, 49-72 months; and mother's age in $18-21$ years, $21-30$ years, and $>30$ years.

\section{Data Analysis}

Statistical analysis was performed using Stata 12.0 software. Descriptive and bivariate analysis were performed for the preliminary evaluation of the association between the predictor variables and the outcome using the Pearson, Fisher or Linear Trend Qui-Square tests, according to the type of variable. For the multivariate analyses, Poisson regression with robust variance was performed [22]. Variables that presented $\mathrm{p}<0.20$ value in the crude analysis were included in the adjusted analysis, obtaining the prevalence ratio $(\mathrm{PR})$ and the $95 \%$ confidence intervals. The variables included in the final model were those that presented a value of $\mathrm{p}<0.05$. 


\section{Results}

Forty-seven binomial mothers and children participated in the study. The response rate was $100 \%$. Malocclusion among the studied children was $41.3 \%$. Malocclusion class I was observed in $58.7 \%$, class II in $34.8 \%$ and class III in $6.5 \%$ of children. Children mostly present open bite $(34.9 \%)$ and anterior maxillary irregularity (47.7\%). Also, increased overjet (47.6\%), anterior crossbite (14.3\%) and deep bite (11.6\%) were present in the sample.

In the childcare group, $51.1 \%$ of children were males, white $(83.0 \%)$ and had $60-72$ months of age (42.6\%). Most of the families (91.5\%) had three minimum wages or less as a monthly income were beneficiaries of the family grant program $(48.9 \%)$ with 1 or 2 children enrolled in the program (80.0\%). Mothers reported having 1 or 2 children $(84.4 \%)$, working $(19.6 \%)$ and had less than 9 years of studies (76.6\%). Children were breastfed exclusively (86.7\%) for more than 12 months (44.2\%), 56.5\% used bottle-feeding and $63.0 \% \%$ pacifier. Most mothers (43.6\%) believe that the ideal age to leave the pacifier should be after the second year of children's life, $42.4 \%$ think that using a pacifier is good for the child, and $68.0 \%$ received information regarding the time of use of the pacifier.

Table 1 presents the results from the bivariate analysis. The number of children in the family $(\mathrm{p}<0.023)$ was significantly associated with greater malocclusion. Malocclusion was associated with longer exclusive breastfeeding $(\mathrm{p}<0.023)$, higher breastfeeding time $(\mathrm{p}<0.001)$, pacifier use $(\mathrm{p}=0.048)$ and higher overhang $(\mathrm{p}<0.032)$.

Table 1. Association between malocclusion and socio-demographic, behavioral and biological factors.

\begin{tabular}{|c|c|c|c|c|}
\hline \multirow{2}{*}{ Variables } & \multicolumn{3}{|c|}{ Malocclusion Present } & \multirow{2}{*}{ p-value } \\
\hline & $\mathbf{N}$ & $\%$ & Total & \\
\hline Sex & & & 19 & 0.211 \\
\hline Female & 7 & 31.8 & & \\
\hline Male & 12 & 50.0 & & \\
\hline Age (Months) & & & 19 & o. $190^{* *}$ \\
\hline $18-35$ & 3 & 37.5 & & \\
\hline $36-48$ & 8 & 42.1 & & \\
\hline $49-72$ & 8 & 42.1 & & \\
\hline Maternal Age (Years) & & & & $0.177^{*}$ \\
\hline $18-21$ & 2 & 50.0 & 19 & \\
\hline $21-30$ & 6 & 27.3 & & \\
\hline$>30$ & 11 & 55.0 & & \\
\hline Income $($ Brazilian Minimum Wage $=$ BMW) & & & 19 & $0.378^{* *}$ \\
\hline$\leq 1 \mathrm{BMW}$ & 11 & 37.9 & & \\
\hline 1-3 BMW & 5 & 38.5 & & \\
\hline 3-5 BMW & 3 & 75.0 & & \\
\hline Family Grant Program & & & 19 & 0.080 \\
\hline No & 13 & 54.2 & & \\
\hline Yes & 6 & 27.3 & & \\
\hline Number of Children Receiving the Family Grant Program & & & 19 & 0.088 \\
\hline $1-2$ & 4 & 21.0 & & \\
\hline $3-4$ & 3 & 60.0 & & \\
\hline Number of Children in the Family & & & 18 & $0.009^{* *}$ \\
\hline 1 & 6 & 31.6 & & \\
\hline 2 & 7 & 38.9 & & \\
\hline 3 & 5 & 71.4 & & \\
\hline Maternal Education (Years) & & & 19 & 0.703 \\
\hline$<9$ & 15 & 42.9 & & \\
\hline$\geq 9$ & 4 & 36.4 & & \\
\hline Maternal Employment & & & 19 & 0.200 \\
\hline
\end{tabular}




\begin{tabular}{|c|c|c|c|c|}
\hline Yes & 5 & 62.5 & & \\
\hline No & 14 & 37.8 & & \\
\hline Breastfeeding & & & 19 & 0.266 \\
\hline Yes & 18 & 46.2 & & \\
\hline No & 1 & 20.0 & & \\
\hline Exclusive Breastfeeding Time (Months) & & & 18 & $0.023^{*} *$ \\
\hline Never was Exclusive & 3 & 50.0 & & \\
\hline$<1$ & 7 & 77.8 & & \\
\hline $1-3$ & 2 & 33.3 & & \\
\hline $3-6$ & 6 & 40.0 & & \\
\hline$>6$ & 0 & 0.0 & & \\
\hline Breastfeeding Time (Months) & & & 18 & $0.001^{* *} *$ \\
\hline$\leq 3$ & 9 & 90.0 & & \\
\hline $3-6$ & 6 & 46.2 & & \\
\hline$\geq 12$ & 3 & 15.8 & & \\
\hline Nursing Bottle Use & & & 18 & 0.805 \\
\hline Yes & 10 & 38.5 & & \\
\hline No & 8 & 42.1 & & \\
\hline Pacifier Use & & & 19 & 0.048 \\
\hline Yes & 15 & 53.6 & & \\
\hline No & 4 & 23.5 & & \\
\hline Overbite & & & 19 & 0.105 \\
\hline Normal & 4 & 23.5 & & \\
\hline Reduce & 3 & 50.0 & & \\
\hline Open Bite & 10 & 66.7 & & \\
\hline Deep Bite & 2 & 40.0 & & \\
\hline Overjet & & & 17 & 0.032 \\
\hline Normal & 2 & 15.4 & & \\
\hline Increase & 12 & 60.0 & & \\
\hline Edge to Edge Bite & 2 & 66.7 & & \\
\hline Anterior Crossbite & 1 & 16.7 & & \\
\hline
\end{tabular}

*Chi-square test; $* * \chi^{2}$ test for linear trend.

Multivariate analysis was performed considering malocclusion and open bite as the main outcomes in two different analyses. Table 2 shows the results of adjusted analysis of malocclusion. A higher prevalence of malocclusion in children was associated with the higher number of children in the family $(\mathrm{PR}=3.93,95 \% \mathrm{CI}$ 1.10-11.49). Children with malocclusion presented a 2.75 higher prevalence of open bite $(\mathrm{PR}=2.75,95 \% \mathrm{CI}$ 1.04-7.32). Children who breastfed more than 12 months had a lower prevalence of malocclusion $(\mathrm{PR}=0.13$, 95\%CI $0.28-0.65)$.

Table 2. Prevalence ratio (PR) crude (c) and adjusted (a) for malocclusion of the children according to socio-demographic, behavioral and biological factors.

\begin{tabular}{|c|c|c|c|c|}
\hline \multirow{2}{*}{ Variables } & \multicolumn{4}{|c|}{ Malocclusion Present } \\
\hline & $\mathrm{PR}^{\mathrm{c}}(95 \% \mathrm{IC})$ & p-value* & $\mathrm{PR}^{\mathrm{a}}(95 \% \mathrm{CI})$ & p-value \\
\hline Sex & & 0.020 & & 0.368 \\
\hline Female & 1.0 & & 1.0 & \\
\hline Male & $0.326(0.12-0.84)$ & & $0.69(0.30-1.56)$ & \\
\hline Family Grant Program & & 0.225 & & 0.989 \\
\hline Yes & 1.0 & & 1.0 & \\
\hline No & $0.63(0.31-1.32)$ & & $0.99(0.40-2.46)$ & \\
\hline Number of Children & & 0.002 & & 0.047 \\
\hline 1 & 1.0 & & 1.0 & \\
\hline 2 & $2.57(0.94-7.06)$ & & $1.32(0.72-2.41)$ & \\
\hline 3 & $10.51(2.44-25.30)$ & & $3.93(1.10-11.49)$ & \\
\hline Maternal Education (Years) & & 0.008 & & 0.236 \\
\hline$<9$ & 1.0 & & 1.0 & \\
\hline$\geq 9$ & $0.40(0.21-0.79)$ & & $0.63(0.30-1.35)$ & \\
\hline
\end{tabular}


Breastfeeding time (Months)

$\leq 3$

$3-12$

$\geq 12$

Overbite

Normal

Reduce

Open bite

Deep bite

Overjet

Normal

Increase

Edge to Edge Bite

Anterior Crossbite

*Variables with $\mathrm{p}>0.20$ in

Table 3 presents the multivariate analysis considering open bite as main outcome. High prevalence of open bite was increased 1.83 times in the pacifier users ( $\mathrm{PR}=1.83,95 \% \mathrm{CI}$ 2.03-6.00). The absence of maternal work was associated with a lower prevalence of open bite $(\mathrm{PR}=0.48,95 \%$ CI 0.26-0.90).

Table 3. Prevalence ratio (PR) crude (c) and adjusted (a) for open bite of the children according to socio-demographic, behavioral and biological factors.

\begin{tabular}{|c|c|c|c|c|}
\hline \multirow{2}{*}{ Variables } & \multicolumn{4}{|c|}{ Open Bite Present } \\
\hline & $\operatorname{PR}^{c}(95 \% I C)$ & p-value* & $\operatorname{PR}^{\mathrm{a}}(95 \% \mathrm{CI})$ & p-value \\
\hline Sex & & 0.149 & & \\
\hline Female & 1.0 & & & \\
\hline Male & $1.66(0.83-3.31)$ & & & \\
\hline Children Age (Months) & & 0.102 & & 0.134 \\
\hline $18-35$ & 1.0 & & 1.0 & \\
\hline $36-48$ & $0.41(0.10-1.75)$ & & $0.66(0.28-1.51)$ & \\
\hline $49-72$ & $0.43(0.10-1.91)$ & & $0.52(0.23-1.91)$ & \\
\hline Family Allowance Program & & 0.826 & & \\
\hline Yes & 1.0 & & & \\
\hline No & $0.93(0.46-1.83)$ & & & \\
\hline Maternal Employment & & 0.021 & & 0.022 \\
\hline Yes & 1.0 & & 1.0 & \\
\hline No & $0.48(0.25-0.89)$ & & $0.48(0.26-0.90)$ & \\
\hline Breastfeeding & & 0.083 & & 0.060 \\
\hline Yes & 1.0 & & 1.0 & \\
\hline No & $1.81(0.93-3.53)$ & & $1.83(0.97-3.47)$ & \\
\hline Pacifier Use & & $<0.001$ & & $<0.001$ \\
\hline Yes & 1.0 & & 1.0 & \\
\hline No & $2.39(1.09-5.23)$ & & $2.11(2.03-6.00)$ & \\
\hline
\end{tabular}

\section{Discussion}

This study found that in children that attended public childcare groups, malocclusion in the deciduous dentition was $41.3 \%$ and presented association with the number of children living in the house and the presence of open bite. Longer breastfeeding time was associated with less prevalence of malocclusion.

In Brazil, studies showed variations between the prevalence of malocclusion in the deciduous dentition between $67.5 \%$ to $87.4 \%$ [1,2,4,6,23,24]. In our study, children with malocclusion were $41.3 \%$, being class I and II malocclusions the more common situations. The study of Vasconcelos et al. [6] observed similar results in children with 5 years of age, malocclusion was $41.7 \%$ being class II malocclusion the more common type. 
These findings can be explained by the multifactoriality of the oral condition that could include biological and/or environment / behavioral factors or their combination as etiological factors [25].

In the present study, the number of children within the families was associated with a higher prevalence of malocclusion in children. Children from families with three children or more presented 4.75 times more prevalence of malocclusion. Another study demonstrated a higher prevalence of malocclusion in children from families with more than two children. The authors explained these findings with possible psychological and emotional factors of those children, who could acquire some unhealthy habits suction habits as a compensation mechanism [26].

Moreover, it was found that a longer time of breastfeeding was associated with a lower chance of malocclusion. A similar result was also found in a study evaluating the prevalence of malocclusion in infancy and breastfeeding, in which children who had been breastfed for more than six months had a lower rate of malocclusion [27]. The World Health Organization recommends exclusive breastfeeding of the baby up to six months of age and maintenance up to two years [28]. Breastfeeding is important for the functional development of the stomatognathic system and the absence of such stimulus can cause impairment in the development of the system [29]. On the other hand, lack of breastfeeding may favor the appearance of deleterious sucking habits, such as pacifier use, leading to the occurrence of malocclusion and open bite.

In our study, open bite was associated with malocclusion. Open bite presence can be associated with non-nutritive sucking habits [4,29]. The lower prevalence of open bite was associated with non-working mothers, similar to the study by Tomita in 2000 [1]. It can be assumed that malocclusion was produced by extrinsic behavioral factors; the presence of the mother can promote better care of the children. The absence of the mothers can promote emotional compensations feelings in the child, translated in the necessity and perpetuation of unhealthy oral habits after three years of age in children [30].

The use of pacifiers was also associated with the presence of open bite. Peres et al. [4] found that the higher frequency and prolonged use of the pacifier were associated with malocclusion. The use of the pacifier could promote inappropriate alignment causing inappropriate palatal growth [4].

The present study has limitations since it is a convenience sample, which means that is representative for the studied population since approximately $80 \%$ of the mothers are residents of the covered area and are followed up in the childcare group. The design of the study, cross-sectional observational, allowed to verify a specific moment in the time not being possible to attributed causality. Although we have included all the mother-child binomials involved in the health unit childcare, the sample size was reduced.

Data of the present study can serve as a baseline for evaluating the effectiveness of interventions and promoting planning of strategies for prevention of diseases through education in oral health with prenatal and childcare groups. Thus, it is recommended to perform long-term studies with a higher sample size to know the impact of health promotion actions regarding malocclusion.

This study reinforces the importance of guiding mothers on factors determining malocclusion since deleterious habits are important factors related to it, so if identified, early malocclusion could be minimized.

\section{Conclusion}

Malocclusion in the group of children with deciduous dentition was high and was associated with a higher number of children, presence of open bite and time of breastfeeding. In addition, open bite was associated with pacifier use, while the lower prevalence of open bite was associated with non-working mothers. Despite the information received by mothers, there is still a lack of knowledge regarding sucking habits. 


\section{Authors' Contributions}

\begin{tabular}{|c|c|c|}
\hline ACJO & (D) https://orcid.org/0000-0002-7884-8197 & $\begin{array}{l}\text { Conceptualization, Methodology, Investigation, Formal Analysis, Project Administration, } \\
\text { Writing - Original Draft. }\end{array}$ \\
\hline TMP & --- & Formal Analysis, Investigation, Writing - Original Draft. \\
\hline DFM & (iD) https://orcid.org/0000-0001-7090-8813 & Conceptualization, Methodology, Investigation, Formal Analysis. \\
\hline CMJ & (iD) https://orcid.org/0000-0003-2413-871X & $\begin{array}{l}\text { Conceptualization, Methodology, Investigation, Formal Analysis, Project Administration, } \\
\text { Resources, Supervision, Writing-Original Draft. }\end{array}$ \\
\hline MMSS & (iD) https://orcid.org/0000-0002-6443-556X & $\begin{array}{l}\text { Conceptualization, Methodology, Investigation, Formal Analysis, Project Administration, } \\
\text { Resources, Supervision, Writing - Original Draft and Writing - Review and Editing. }\end{array}$ \\
\hline RGL & https://orcid.org/0000-0003-1006-3809 & $\begin{array}{l}\text { Conceptualization, Methodology, Investigation, Formal Analysis, Project Administration, } \\
\text { Resources, Supervision, Writing - Original Draft and Writing - Review and Editing. }\end{array}$ \\
\hline
\end{tabular}

\section{Financial Support}

None.

\section{Conflict of Interest}

The authors declare no conflicts of interest.

\section{Data Availability}

The data used to support the findings of this study can be made available upon request to the corresponding author.

\section{References}

[1] Tomita NE, Bijella VT, Franco LJ. The relationship between oral habits and malocclusion in preschool children. Rev Saude Publica 2000; 34(3):299-303. https://doi.org/10.1590/s0034-89102000000300014

[2] Carvalho AC, Paiva SM, Scarpelli AC, Viegas CM, Ferreira FM, Pordeus IA. Prevalence of malocclusion in primary dentition in a population-based sample of Brazilian preschool children. Eur J Paediatr Dent 2011; 12(2):107-11.

[3] Karjalainen S, Ronning O, Lapinleimu H, Simell O. Association between early weaning, non-nutritive sucking habits and occlusal anomalies in 3-year-old Finnish children. Int J Paediatr Dent 1999; 9(3):169-73. https://doi.org/10.1046/j.1365-263x.1999.00133.x

[4] Peres KG, Barros AJ, Peres MA, Victora CG. Effects of breastfeeding and sucking habits on malocclusion in a birth cohort study. Rev Saude Publica 2007; 41(3):343-50. https://doi.org/10.1590/s0034-89102007000300004

[5] Pipa Vallejo A, Cuerpo García de los Reyes P, López-Arranz Monje E, González García M, Pipa Muñiz I, Acevedo Prado A. Prevalence of malocclusion in order to non nutritive sucking habits in children between 3 and 12 years-old in Ferrol. Av Odontoestomatol 2011; 27(3):137-45.

[6] Vasconcelos FM, Massoni AC, Heimer MV, Ferreira AM, Katz CR, Rosenblatt A. Non-nutritive sucking habits, anterior open bite and associated factors in Brazilian children aged 30-59 months. Braz Dent J 2011; $22(2): 140-5$. https://doi.org/10.1590/So103-64402011000200009

[7] Brasil. SB BRASIL 2010. Pesquisa Nacional de Saúde Bucal. Resultados Principais. Brasília: Ministério da Saúde; 2012. 116p. [In Portuguese]

[8] Moimaz SA, Garbin AJ, Lima AM, Lolli LF, Saliba O, Garbin CA. Longitudinal study of habits leading to malocclusion development in childhood. BMC Oral Health 2014; 14:96. https://doi.org/10.1186/1472-6831-14-96

[9] Chen X, Xia B, Ge L. Effects of breast-feeding duration, bottle-feeding duration and non-nutritive sucking habits on the occlusal characteristics of primary dentition. BMC Pediatr 2015; 15:46. https://doi.org/10.1186/s 12887-015-0364-1

[10] Wagner Y, Heinrich-Weltzien R. Occlusal characteristics in 3-year-old children--results of a birth cohort study. BMC Oral Health 2015; 15:94. https://doi.org/10.1186/s12903-015-0080-0

[11] de Vis H, De Boever JA, van Cauwenberghe P. Epidemiologic survey of functional conditions of the masticatory system in Belgian children aged 3-6 years. Community Dent Oral Epidemiol 1984; 12(3):203-7. https://doi.org/10.1111/j.1600-0528.1984.tbo1440.x

[12] Warren JJ, Bishara SE. Duration of nutritive and nonnutritive sucking behaviors and their effects on the dental arches in the primary dentition. Am J Orthod Dentofacial Orthop 2002; 121(4):347-56. https://doi.org/10.1067/mod.2002.121445

[13] Melink S, Vagner MV, Hocevar-Boltezar I, Ovsenik M. Posterior crossbite in the deciduous dentition period, its relation with sucking habits, irregular orofacial functions, and otolaryngological findings. Am J Orthod Dentofacial Orthop 2010; 138(1):32-40. https://doi.org/10.1016/j.ajodo.2008.09.029

[14] de Albuquerque SS, Duarte RC, Cavalcanti AL, Beltrao EM. The influence of feeding methods in the development of nonnutritive sucking habits in childhood. Cien Saude Colet 2012; 15(2):371-8.

https://doi.org/10.1590/S1413-81232010000200012 
[15] Farsi NM, Salama FS. Sucking habits in Saudi children: prevalence, contributing factors and effects on the primary dentition. Pediatric Dent 1997; 19(1):28-33.

[16] Roig AO, Martinez MR, Garcia JC, Hoyos SP, Navidad GL, Alvarez JC, et al. Factors associated to breastfeeding cessation before 6 months. Revista Latino-Am Enfermagem 2010; 18(3):373-80. https://doi.org/10.1590/S0104-11692010000300012

[17] Bonilha LRCM, Rivorêdo CRSF. Puericultura: duas concepções distintas. J Pediatr 2005; 81(1):7-13. https://doi.org/10.2223/1276

[18] Sousa JP, Sousa SA. Prevalence of malocclusion in 7-9-years-old children from Pole 1 of municipal schools in João Pessoa-PB. Rev Odontol UNESP 2013; 42(2):117-23. https://doi.org/10.1590/S1807-25772013000200009

[19] Brasil. Saúde da Criança: Acompanhamento do Crescimento e Desenvolvimento Infantil. Brasília: Ministério da Saúde; 2002. 100p. [In Portuguese].

[20] Instituto Brasileiro de Geografia e Estatística. Características da população e domicílios - Resultados do Universo Notas metodológica. Rio de Janeiro: Instituto Brasileiro de Geografia e Estatística; 2010. [In Portuguese]

[21] Peres KG, Traebert ESdA, Marcenes W. Differences between normative criteria and self-perception in the assessment of malocclusion. Rev Saúde Pública 2002; 36(2):230-6. https://doi.org/10.1590/S0034-89102002000200016

[22] Victora CG, Huttly SR, Fuchs SC, Olinto MT. The role of conceptual frameworks in epidemiological analysis: a hierarchical approach. Int J Epidemiol 1997; 26(1):224-7. https://doi.org/10.1093/ije/26.1.224

[23] Chevitarese AB, Della Valle D, Moreira TC. Prevalence of malocclusion in 4t-6 year old Brazilian children. J Clin Pediatr Dent 2002; 27(1):81-5. https://doi.org/10.17796/jcpd.27.1.an436m284201571p

[24] Frazao P, Narvai PC, Latorre Mdo R, Castellanos RA. Malocclusion prevalence in the deciduous and permanent dentition of schoolchildren in the city of Sao Paulo, Brazil, 1996. Cad Saúde Publica 2002; 18(5):1197-205. https://doi.org/10.1590/So102-311X2002000500012

[25] Joshi N, Hamdan AM, Fakhouri WD. Skeletal malocclusion: a developmental disorder with a life-long morbidity. J Clin Med Res 2014; 6(6):399-408. https://doi.org/10.14740/jocmr 1905w

[26] Almeida T. Family context, malocclusion and oral habits in preschool children living in areas assisted by Family Health Strategy, Salvador, State of Bahia, Brazil. Rev Odontol UNESP 2012; 41(4):226-35.

[27] Gimenez C. First childhood malocclusion's prevalence and its relation with breast feeding and oral habits. Rev Dent Press Ortodon Ortop Facial 2000; 13(2):70-83. https://doi.org/10.1590/S141 5-54192008000200009

[28] World Health Organization. Breastfeeding. World Health Organization; 2018.

[29] Moimaz SA, Zina LG, Saliba NA, Saliba O. Association between breast-feeding practices and sucking habits: a crosssectional study of children in their first year of life. J Indian Soc Pedod Prev Dent 2008; 26(3):102-6. https://doi.org/10.4103/0970-4388.43188

[30] Campos F. The malocclusion and its association with socioeconomic variables, habits and care with five years old children. Rev Odontol UNESP 2013; 42(3):160-6. 